\title{
Percutaneous laser ablation for benign and malignant thyroid diseases
}

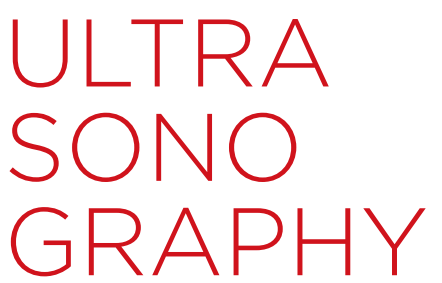

\author{
Giovanni Mauri', Luca Nicosia², Paolo Della Vigna', Gianluca Maria Varano', \\ Daniele Maiettini ${ }^{1}$, Guido Bonomo ${ }^{1}$, Gioacchino Giuliano ${ }^{3}$, Franco Orsi ${ }^{1}$, Luigi Solbiati ${ }^{4}$, \\ Elvio De Fiori ${ }^{5}$, Enrico Papini ${ }^{6}$, Claudio Maurizio Pacella ${ }^{7}$, Luca Maria Sconfienza ${ }^{8,9}$ \\ ${ }^{1}$ Department of Interventional Radiology, European Institute of Oncology, Milan; \\ ${ }^{2}$ Postgraduation School in Radiodiagnostics, Università degli Studi di Milano, Milan; ${ }^{3}$ Thyroid \\ Cancer Unit, European Institute of Oncology, Milan; ${ }^{4}$ Department of Radiology, Humanitas \\ University, IRCCS Humanitas Clinical and Research Hospital, Rozzano; ${ }^{5}$ Department of \\ Radiology, European Institute of Oncology, Milan; ${ }^{6}$ Endocrinology Department, Regina \\ Apostolorum Hospital, Albano Laziale; ${ }^{7}$ Department of Diagnostic Imaging and Interventional \\ Radiology, Regina Apostolorum Hospital, Rome; ${ }^{8}$ Unit of Diagnostic and Interventional \\ Radiology, IRCCS Istituto Ortopedico Galeazzi, Milan; ${ }^{9}$ Department of Biomedical Sciences \\ for Health, University of Milano, Milan, Italy
}

Minimally invasive image-guided thermal ablation is becoming increasingly common as an alternative to surgery for the treatment of benign thyroid nodules. Among the various techniques for thermal ablation, laser ablation (LA) is the least invasive, using the smallest applicators available on the market and enabling extremely precise energy deposition. However, in some cases, multiple laser fibers must be used simultaneously for the treatment of large nodules. In this review, the LA technique is described, and its main clinical applications and results are discussed and illustrated.

Keywords: Ultrasonography; Thyroid gland; Laser therapy; Thyroid nodule

\section{Introduction}

Thyroid nodules are a very common occurrence in the general population, with a prevalence ranging between $20 \%$ and $76 \%$ [1]. The vast majority of thyroid nodules are benign and incidentally detected. Thyroid cancer is relatively uncommon, accounting for approximately $1 \%-5 \%$ of all cancers in females and fewer than $2 \%$ in males [2]. Benign thyroid nodules generally do not require any treatment, unless discomfort, dyspnoea, and hoarseness are present, when nodules present cosmetic concerns $[3,4]$, or in cases of hyperfunctioning nodules [5]. The standard treatment of benign thyroid nodules still remains surgical resection $[4,6]$; however, this is a major surgical procedure, requiring general anaesthesia and hospitalization, with the complication rate ranging from $2.5 \%$ to $8.1 \%$ [7]. Further, skin scarring around the neck may be an undesired result of this type of surgery. In these cases, image-guided thermal ablation (IGTA) has been successfully used to achieve volumetric

\section{REVIEW ARTICLE}

https://doi.org/10.14366/usg. 18034 pISSN: 2288-5919 • elSSN: 2288-5943 Ultrasonography 2019;38:25-36

Received: June 15, 2018

Revised: September 15, 2018 Accepted: September 17, 2018

Correspondence to: Giovanni Mauri, MD, Division of Interventional Radiology, European Institute of Oncology, via Ripamonti 435, Milan, Italy

Tel. +39-02-574891

Fax. +39-02-57489 (208)

E-mail: giovanni.mauri@ieo.it

This is an Open Access article distributed under the terms of the Creative Commons Attribution NonCommercial License (http://creativecommons.org/ licenses/by-nc/3.0/) which permits unrestricted noncommercial use, distribution, and reproduction in any medium, provided the original work is properly cited.

Copyright (C) 2019 Korean Society of Ultrasound in Medicine (KSUM)

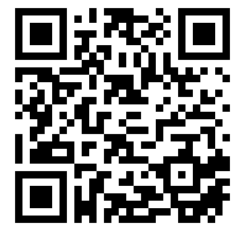

How to cite this article:

Mauri G, Nicosia L, Vigna PD, Varano GM Maiettini D, Bonomo G, et al. Percutaneous laser ablation for benign and malignant thyroid diseases. Ultrasonography. 2019 Jan;38(1):25-36. 
nodule reduction and symptom improvement [8-11]. IGTA is minimally invasive and has been reported to have good clinical results, thus indicating its potential to replace surgery as the firstchoice treatment for benign thyroid nodules [12]. Moreover, IGTA techniques have been used in limited series for the treatment of malignant thyroid cancers, and in cases of recurrence after surgical excision of a primary cancer [13-19]. In this setting, IGTA still plays a limited role, but it represents a fascinating additional treatment within a multidisciplinary approach to thyroid cancer. Recently, new guidelines have been released by the Korean Society of Thyroid Radiology, including suggestions on indications for radiofrequency ablation (RFA) for benign and recurrent cancers [20]. This paper includes the most recent and authoritative indications and guidelines on the topic of IGTA in thyroid disease, which can also be applied to other modalities than RFA. Notably, as several other IGTA techniques have been applied in the treatment of thyroid diseases [11], and different specialists (radiologists, surgeons, endocrinologists) are currently performing IGTA, a more homogeneous standardization of indications, techniques, and even reporting criteria would be useful [21].

Percutaneous laser ablation (LA) was one of the first techniques used to perform IGTA, and is currently used in several different clinical scenarios, where its low invasiveness and high precision might offer clinical advantages over other ablative techniques [2225]. LA was also one of the first techniques used for thyroid thermal ablation, and its use has been reported in the treatment of benign, hyperfunctioning, and malignant thyroid diseases [24,26-30]. In this paper, we review the application of LA in the thyroid, discussing its main clinical applications, results, and limitations.

\section{LA Technique}

The term "laser" originated as an acronym for "light amplification by stimulated emission of radiation." Laser light is highly coherent, collimated, and monochromatic, and can be precisely focused to deliver a high amount of energy to a very small area [31]. Laser light can be vehiculated from the source to a different point through an optical fibre, which can be designed according to the desired final energy delivery in terms of material, length, and tip shape $[32,33]$. When interacting with biological tissues, laser light undergoes scattering and is absorbed by tissues, with consequent deposition of energy and a controlled local increase in temperature [34].

Different laser sources (such as diodes or neodymium-yttrium aluminium garnet) and wavelengths can be used for clinical applications. For human therapies, the 1,064 nm wavelength seem to be ideal because of its properties in terms of tissue penetration and absorption. Thermal increases in temperature can cause tissue destruction by means of various mechanisms, including tissue carbonization and coagulative necrosis $[35,36]$. Irreversible cellular damage requires temperature exposure for a certain amount of time; it generally begins at a temperature of $46^{\circ} \mathrm{C}$ when cells are exposed for about 60 minutes. At temperatures between $60^{\circ} \mathrm{C}$ and $100^{\circ} \mathrm{C}$, fast and permanent protein coagulation takes place, while temperatures over $105^{\circ} \mathrm{C}-110^{\circ} \mathrm{C}$ induce tissue carbonization and vaporization [36-38].

\section{Procedure}

For the treatment of benign thyroid nodules with $L A$, the patient is placed on the operating table in the supine position with a hyperextended neck, peripheral venous access is obtained, and vital parameters are monitored.

Before treatment, the size, shape, and vascularization of the thyroid nodule are assessed using ultrasound. This preliminary evaluation needs to plan the number of fibers to use, the preferred access route, and the number of illuminations needed, according to nodule volume. A needle path as parallel as possible to the longest axis of the nodule is preferred. The procedure is performed using commercial ultrasound systems and a high-frequency linear transducer. A needle-guided attachment with adjustable angle selection can be used to help the operator with needle insertion to achieve a homogeneous distribution of up to five fibers in the nodule. The procedure is generally performed with local anaesthesia ( $2-5 \mathrm{mg}$ of $2 \%$ lidocaine) and/or under conscious sedation, even though some authors prefer not to use any kind of anaesthesia, in order to better monitor the procedure during ablation [39]. Once the procedure has been planned, one or more 21-G introducer needles are placed in the deeper portion of the target nodule under realtime ultrasound guidance. If multiple insertions are performed, a distance of approximately $1 \mathrm{~cm}$ is maintained between the fibers $[40,41]$. Then, a plane-cut quartz optical fiber is inserted and advanced up to the introducer needle tip. The introducer needle is then partially retracted to expose the fiber tip by at least $5 \mathrm{~mm}$. A safety distance of about 10-15 mm should be left between the fiber tip and any critical structures to avoid potential complications. The first illumination is generally directed into the deepest part of the nodule, with a fixed power protocol of $3 \mathrm{~W}$, and a total energy delivered for each fiber/illumination between 1,200 and 1,800 J. During treatment, gas formation is continuously monitored in real time with ultrasound. Laser fibers are subsequently retracted one or more times to cover the entire volume of the nodule. This technique is also known as the "pull-back technique," and has the advantage of reducing the number of direct punctures of the nodule, the invasiveness of the procedure, and patients' discomfort. 
After ablation is completed, contrast-enhanced ultrasonography (CEUS) can be performed in order to precisely assess the ablated volume, and in case of residual vital tissue, ablation can be completed under CEUS guidance [42-44]. Patients are generally kept under observation for a couple of hours after the procedure

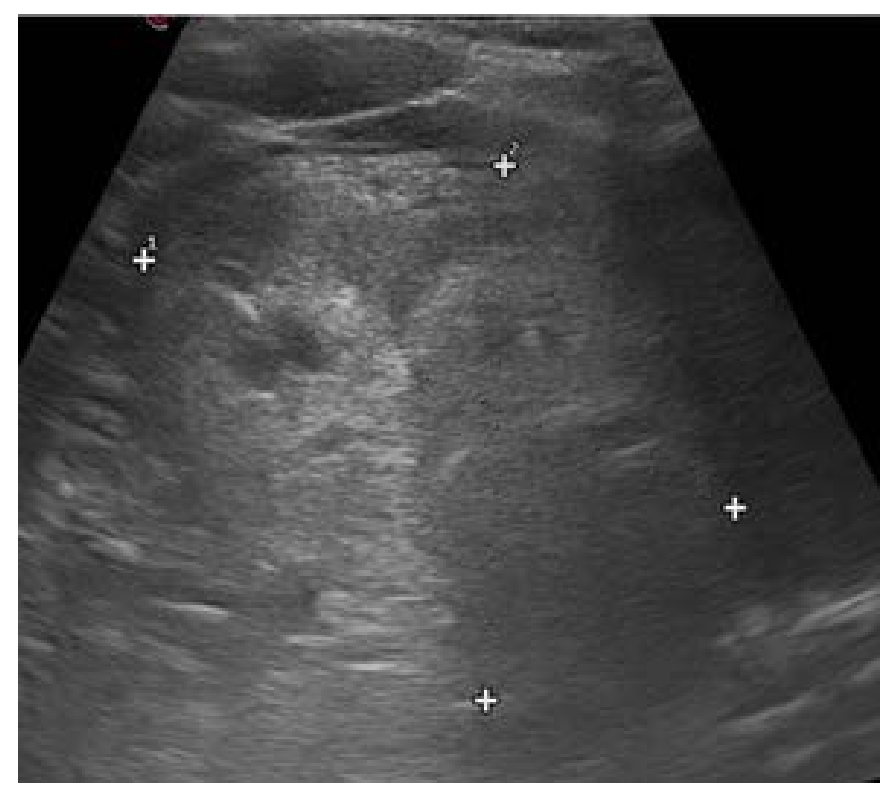

A

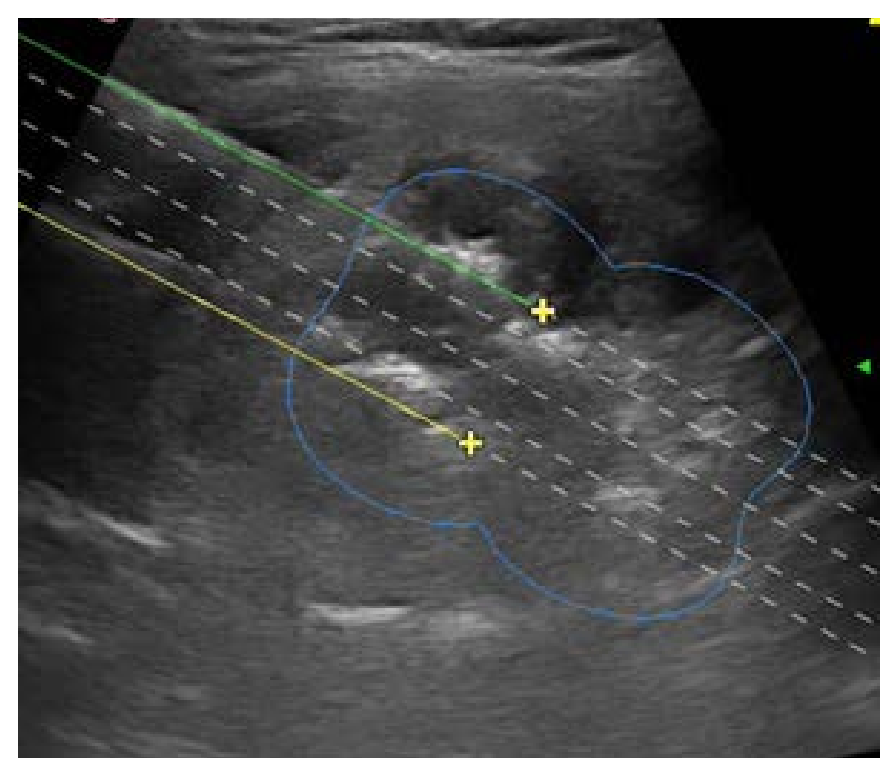

C and then discharged from the hospital. Two cases of benign thyroid nodule treatment with LA are shown in Figs. 1 and 2.

Unlike benign nodules, the purpose of treating malignant nodules is to ablate the whole nodule volume, including safe margins of at least 3-5 mm. This implies the need for additional care in the

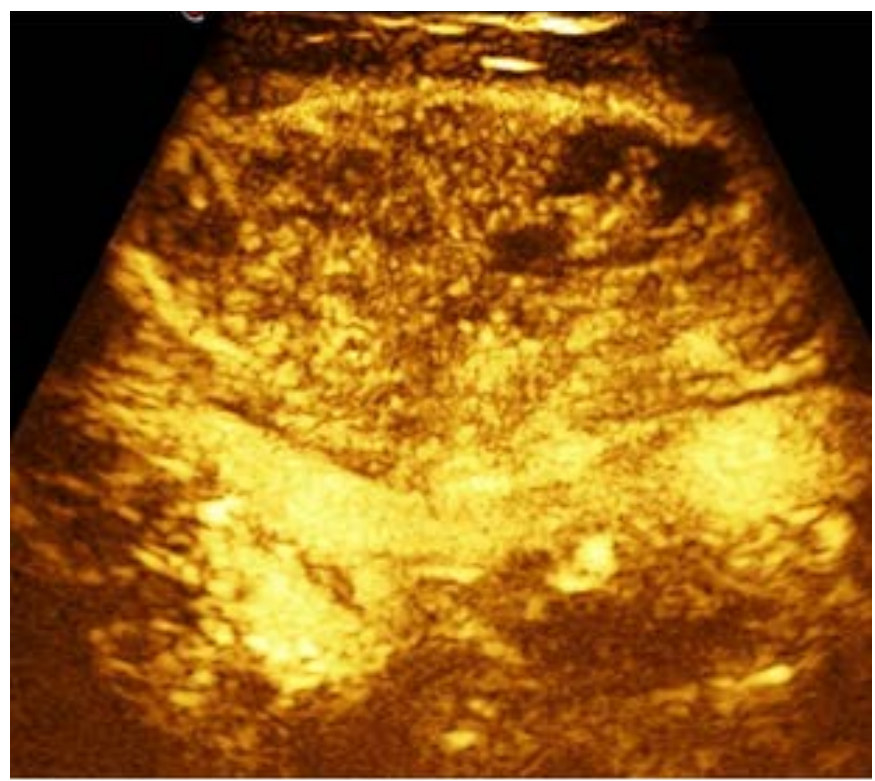

B

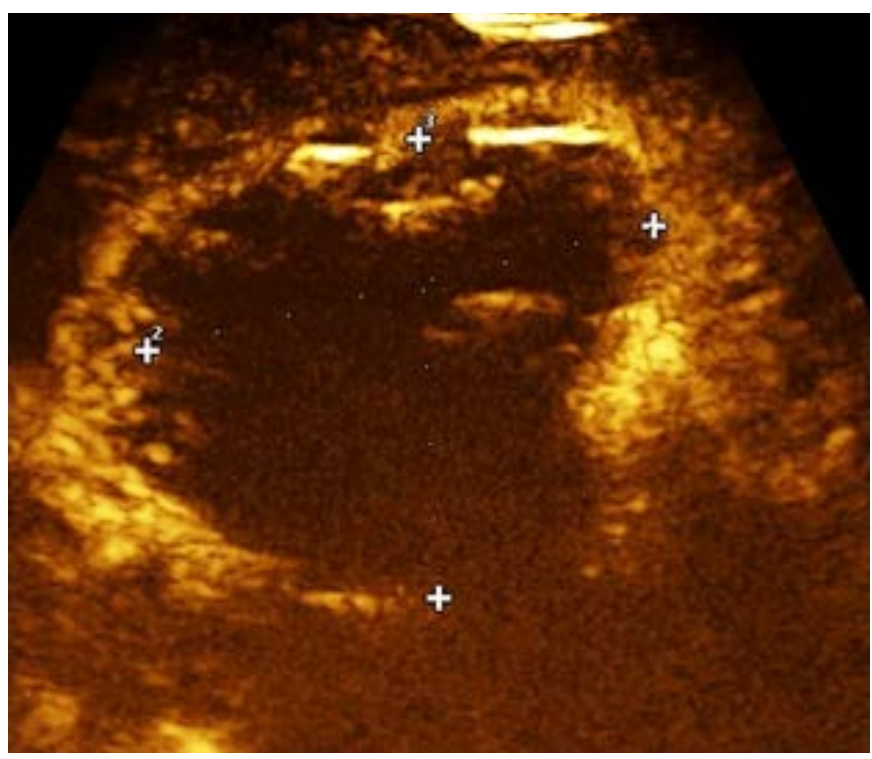

D

Fig. 1. Ultrasonography showing laser treatment of a 62-year-old patient with a benign thyroid nodule.

A. Ultrasonography scan before treatment demonstrates a large, isoechoic, non-homogeneous thyroid nodule. B. Contrast-enhanced ultrasonography of the same nodule before treatment shows intense enhancement of the nodule. C. Ultrasonography during treatment shows the insertion of two laser fibers with the use of dedicated planning software. Hyperechoic areas due to gas formation are seen around the needle tips (green and yellow lines, yellow markers, and blue circle line indicate expected fiber path, expected position of needle tip, and expected area of ablation with 1 pull-back, respectively). D. Contrast-enhanced ultrasonography performed after treatment demonstrates lack of enhancement in the treated area (markers). 
identification and preservation of the surrounding vital structures. Ideally, malignant nodules should be at least $5 \mathrm{~mm}$ distant from the thyroid capsule for LA to be suitable. Ablation is then performed with the same protocol described above to treat benign nodules
[16]. However, in this setting, the use of CEUS is of paramount importance, as it allows the detection of areas of the nodule that still need to be treated $[45,46]$.

In cases of recurrent thyroid tumours or lymph node metastases,

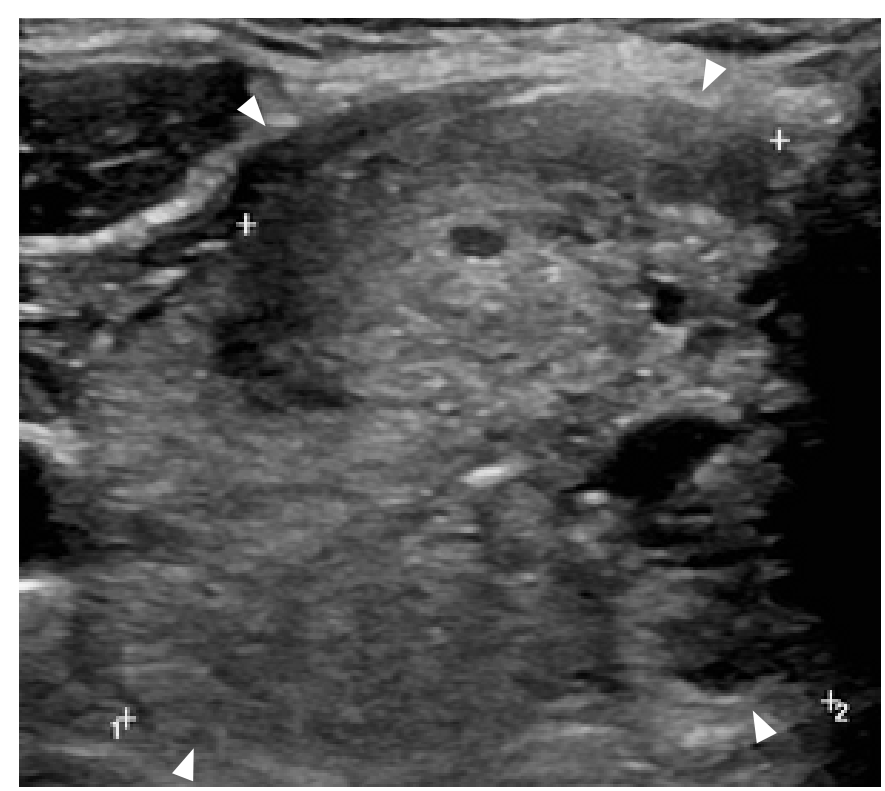

A

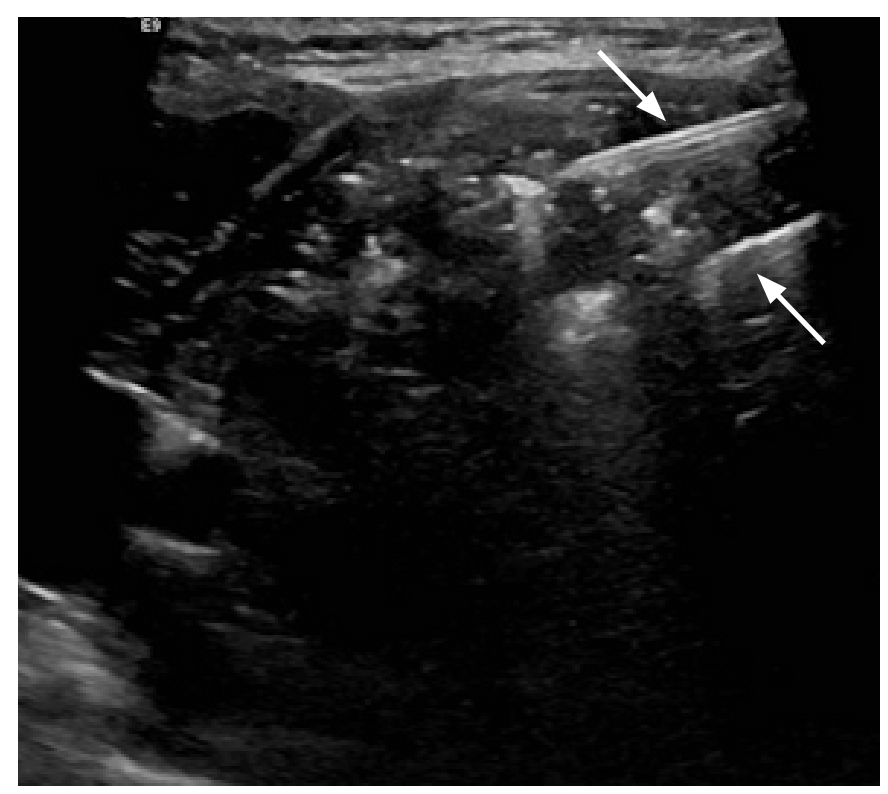

C

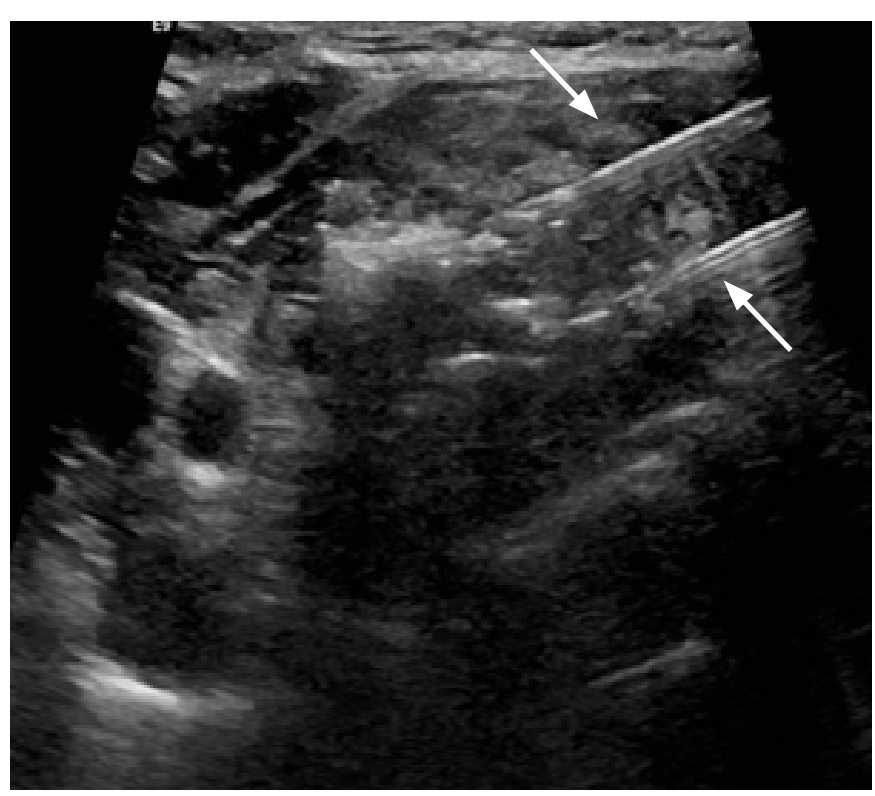

B

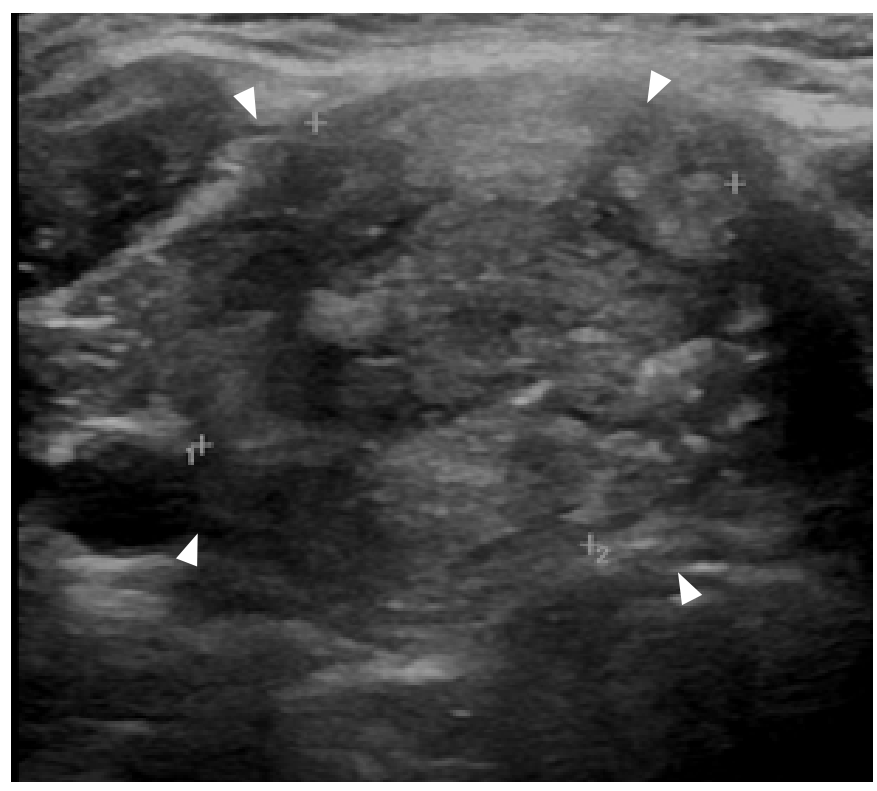

D

Fig. 2. Ultrasonography of a 62-year-old patient with a benign thyroid nodule treated with laser ablation.

A. Ultrasonography shows a large, isoechoic, non-homogeneous, predominantly solid thyroid nodule (arrowheads). B. Ultrasonography during treatment shows two parallel laser fibers that are clearly visible as hyperechoic lines (arrows), and hyperechoic areas due to gas formation during ablation around the tip of the laser fibers. C. Ultrasonography after one pull-back of the two laser (arrows) fibers shows the two laser fibers visible as hyperechoic lines, while an area of non-homogeneous hyperechogenicity is seen in the previously ablated area, corresponding to residual gas after treatment. D. Ultrasonography taken 2 months after treatment demonstrates a $58 \%$ volumetric reduction of the treated nodules, which appear as isoechoic and non-homogeneous (arrowheads). 
target lesions can be adjacent to critical structures. In such cases, a variable amount of fluid solution ("hydrodissection") can be injected between the lesion and the structure to preserve to increase their distance [47-49]. Then, ablation can be performed with a $3 \mathrm{~W}$ fixed protocol and 1,200-1,800 J, with one or multiple fibers. Ultrasound monitoring and CEUS are crucial for the safety and success of this procedure, while fusion imaging might help increase visibility for deeper lesions $[24,46,50,51]$. A case of a recurrent thyroid cancer treated with LA is shown in Fig. 3.

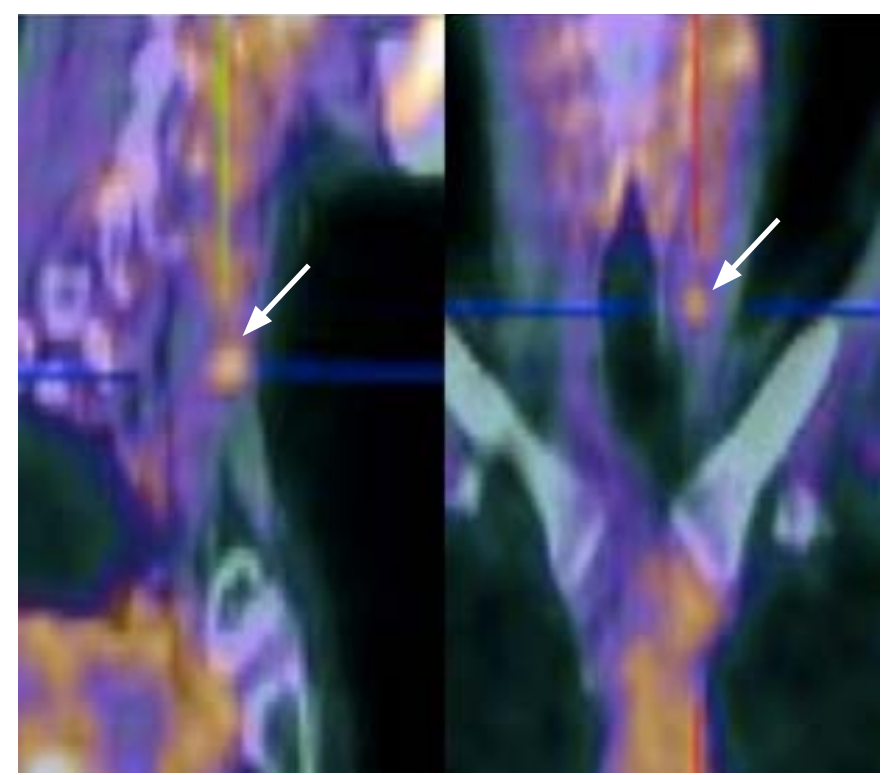

A

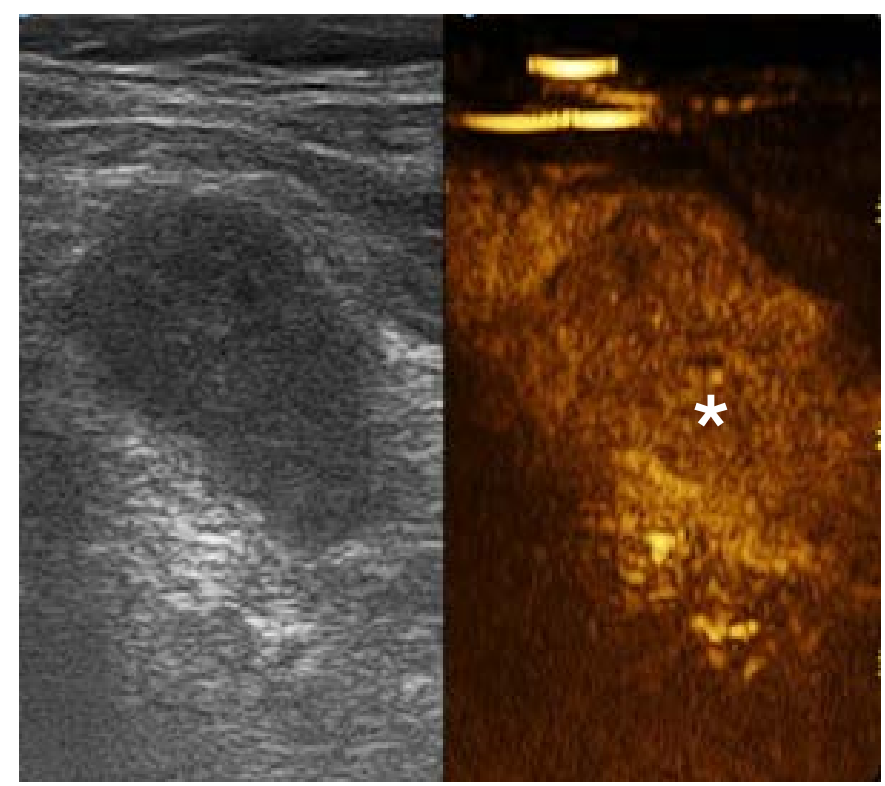

C

Fig. 3. 18-Fludeoxyglucose positron emission tomography $\left({ }^{18} \mathrm{FDG}\right.$-PET) and ultrasonography in a 73 -year-old patient with previous papillary thyroid carcinoma and a cytologically proven metastatic lymph node treated with laser ablation.

A. ${ }^{18}$ FDG-PET scan shows a left cervical area of focal intense uptake (arrows) representing a metastatic lymph node. B. Ultrasonography performed at the same level shows a hypoechoic oval-shaped lymph node, with loss of normal nodal appearance (arrow; c, carotid artery). C. Contrast-enhanced ultrasonography demonstrates intense enhancement of the lymph node (asterisk). D. Ultrasonography during the treatment shows two laser fibers, visible as hyperechoic lines (arrows), extending into the lymph node. 


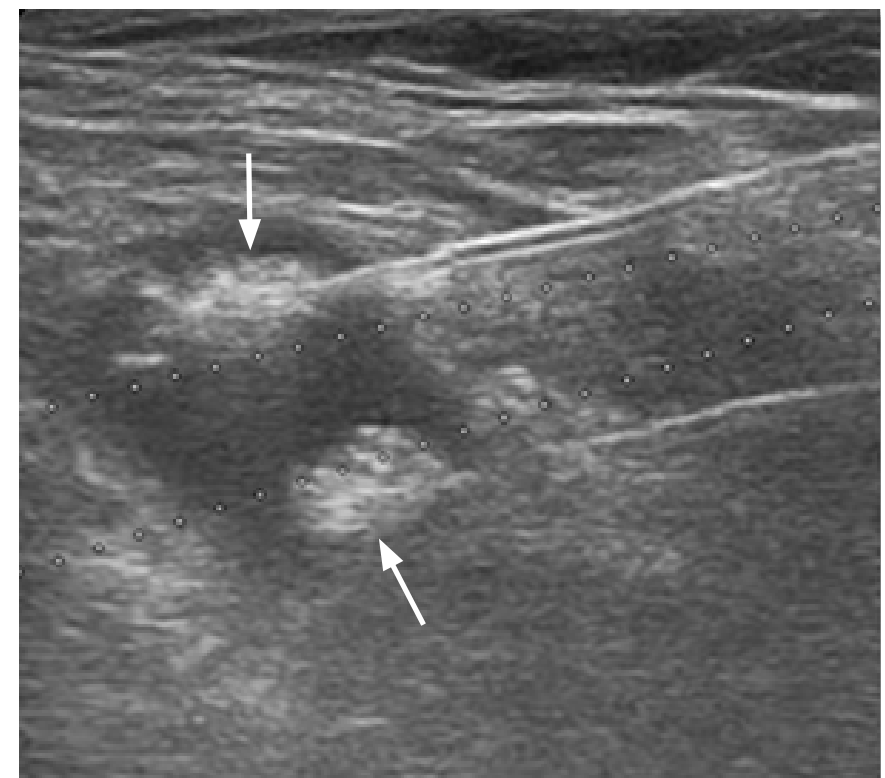

$\mathrm{E}$

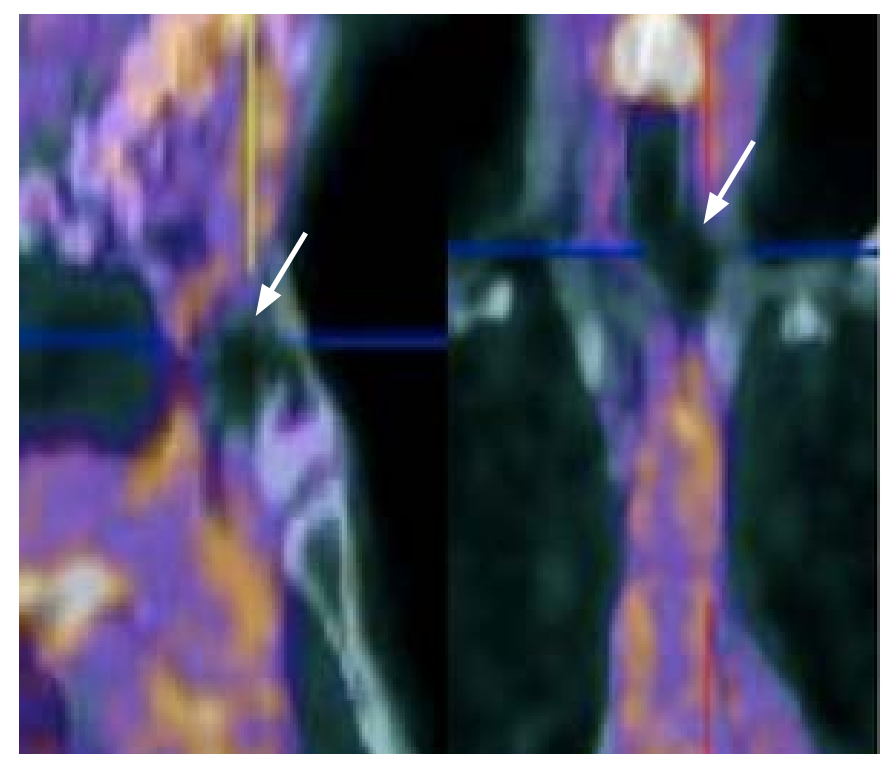

G

\section{Results of LA in the Thyroid}

\section{Benign Nodules}

Several papers on initial experiences demonstrated the efficacy of $L A$ for inducing volume shrinkage of benign thyroid nodules over time. In 2007, a prospective randomized controlled trial by Papini et al. [52] analyzed 1-year changes in nodule volume and the modification of local symptoms in patients with benign solid thyroid nodules randomly assigned to LA, levothyroxine therapy, or observation. The authors found significant nodule volume reduction (change in volume, $-5.2 \pm 3.1 \mathrm{~mL}$ vs. $-0.6 \pm 2.2 \mathrm{~mL}$ vs. $0.7 \pm 2.2 \mathrm{~mL}$,

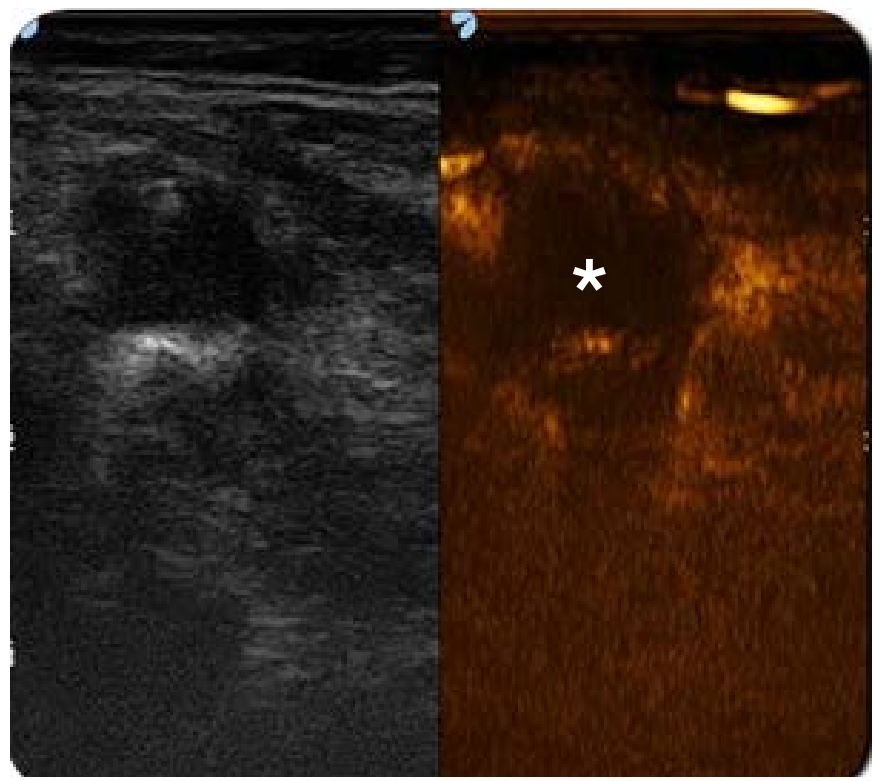

$\mathrm{F}$

Fig. 3. E. Ultrasonography during ablation shows two hyperechoic areas around the tip of the two laser fibers (arrows), reflecting gas formation during ablation. F. Post-treatment contrast-enhanced ultrasonography demonstrates the lack of enhancement in the treated lymph node (asterisk). G. ${ }^{18} \mathrm{FDG}$-PET after treatment shows no uptake at the level of the previously treated lymph node (arrows).

respectively), with good treatment toleration by patients and better improvement of local symptoms in the LA group than in controls ( $81 \%$ vs. $13.3 \%$ vs. $0 \%$ ) [52]. A retrospective study by Achille et al. [43] reported a mean nodule volume reduction from $24.2 \pm 19.4 \mathrm{~mL}$ to $6.2 \pm 6.6 \mathrm{~mL}$ at 6 months $(P<0.001)$ and to $4.5 \pm 5.2 \mathrm{~mL}$ at 12 months $(P<0.001)$, with an overall mean nodule volume reduction at the end of the study of $84 \% \pm 13 \%$. Complete resolution of cosmetic concerns was found in $87 \%$ of participants, and pressure symptoms were resolved in 88\% [43].

The volume reduction achieved with LA has been shown to be stable over time, with protracted clinical benefits even after 
a single treatment. A prospective multicentre randomized trial investigating the long-term results of LA of benign thyroid nodules reported volume reduction in comparison with the baseline volume of $49 \% \pm 22 \%, 59 \% \pm 22 \%, 60 \% \pm 24 \%$, and $57 \% \pm 25 \%$ at 6,12 , 24 , and 36 months, respectively $(\mathrm{P}<0.001)$. The 36 -month followup documented $\mathrm{a} \geq 50 \%$ reduction in $67.3 \%$ of the treated nodules $(\mathrm{P}<0.001)$. At that time, local pressure symptoms were present in $8 \%$ of patients, compared to $38 \%$ at baseline [30]. Approximately $5 \%$ of the nodules treated with LA presented partial regrowth over time. A retrospective study by Dossing et al. [53] analyzed 78 patients with a benign solitary solid nodule treated by LA and observed them for a mean follow-up of 36 months (range, 12 to 96 months). The overall median nodule volume decreased from $8.2 \mathrm{~mL}$ (range, 2.0 to $25.9 \mathrm{~mL}$ ) to $3.5 \mathrm{~mL}$ (range, 0.6 to $17.6 \mathrm{~mL}$ ) after 12 months $(\mathrm{P}<0.001)$ and to $4.1 \mathrm{~mL}$ (range, 0.6 to $33.0 \mathrm{~mL} ; \mathrm{P}=0.001$ ) at the final evaluation. At that time, the median reduction was $51 \%$ (range, $-194 \%$ to $95 \%$ ). Almost all patients included in the study had pressure symptoms, which disappeared in $84 \%$ of cases. Cosmetic concerns disappeared in $72 \%$ of patients. Both the self-reported pressure symptoms $(r=0.4, P=0.02)$ and the cosmetic complaints $(r=0.3, P=0.02)$ were significantly correlated with nodule volume reduction after LA [53]. In a prospective, single-centre study, Oddo et al. [54] investigated changes in quality of life after LA treatment of benign thyroid nodules. The authors reported a significant improvement of visual analogue scale scores in all patients after 1 week, and a significant improvement in goitre symptoms and in the general score after 1 and 6 months, as evaluated by the Thyroidspecific Patient Reported Outcome questionnaire.

One of the main issues of IGTA in benign thyroid nodules is the possible regrowth of the treated nodule over time [20]. With LA as well, regrowth of the marginal unablated nodule tissue may occur, and particularly in case of initially large nodules, subsequent treatment can be necessary [55]. As a general rule, retreatment is indicated in cases of incomplete symptom relief, volumetric reduction $<50 \%$, and nodule re-growth [20]. Compared with other ablation techniques, such as RFA, LA seems to provide similar results, with a possible trend for a lower complication rate and less discomfort. In 2015, a systematic review including traditional pooling and a Bayesian network meta-analysis of the comparative efficacy of RFA and LA was published, reporting apparent superiority of RFA in reducing benign thyroid nodule volume [56]. However, that paper was based on old results on LA (up to 2007), and mainly on the experiences of a single centre ( 5 out of 7 papers in the LA group were from the same centre). Subsequently, in a single-centre study comparing 90 patients treated with percutaneous LA or RFA by the same group of operators, no difference in the time course of the relative volume reduction between the two techniques was found
[40]. A recent multicentre study, aimed at comparing the effect of LA and RFA through a propensity score matching analysis, evaluated data from 601 consecutive patients (449 LA and 152 RFA). In that study, the mean nodule volume decreased from $21.5 \pm 16.5 \mathrm{~mL}$ at baseline to $8.7 \pm 7.7 \mathrm{~mL}(\mathrm{P}<0.001)$ and to $8.0 \pm 7.2 \mathrm{~mL}(\mathrm{P}<0.001)$ at 6 and 12 months, respectively, in patients who underwent $L A$, and from $24.5 \pm 17.9 \mathrm{~mL}$ at baseline to $11.3 \pm 10.7 \mathrm{~mL}(\mathrm{P}<0.001)$ and to $9.9 \pm 9.5 \mathrm{~mL}(\mathrm{P}<0.001)$ at 6 and 12 months, respectively, in patients who underwent RFA. No significant differences in volume reduction at different time points was found between the two groups [57]. Therefore, based on the more recent literature, the two techniques can be considered equivalent in terms of results for nodule volume reduction when performed by experienced operators.

The safety of LA has been investigated in several studies, which have found high levels of tolerability and low numbers of major complications. A multicentre retrospective analysis of 1,837 treatments from eight centres found an overall complication rate of $0.9 \%$, with no life-threatening complications [55]. Major complications occurred in $0.5 \%$ of cases (8 patients), and all consisted of voice changes due to vocal cord palsy, with complete recovery after 3 months. Minor complications were reported in $0.5 \%$ of cases (9 patients), including subcapsular or perithyroidal hematoma and skin burn. Pain was the most frequent side effect of LA and was recorded as mild or moderate, respectively, in $10.6 \%$ and $1.6 \%$ of patients.

LA can also be successfully used to treat patients with benign hyperfunctioning thyroid nodules. In a recent paper, Gambelunghe et al. [28] reported 3-year results after LA of 82 patients with hyperfunctioning thyroid nodules. They found significant volume reduction of the treated nodules from $12 \mathrm{~mL}$ (range, 5 to $118 \mathrm{~mL}$ ) to $5 \mathrm{~mL}$ (range, 1.2 to $40 \mathrm{~mL}$ ) after 3 years $(P<0.001)$. Notably, better results were achieved in smaller $(<15 \mathrm{~mL})$ nodules, where the percentage of ablated tissue was higher. Thus, with proper patient selection, LA also seems to be a valuable alternative for the treatment of hyperfunctioning thyroid nodules [58]. Furthermore, a recent pilot study comparing outcomes in patients with large toxic nodules treated with LA followed by ${ }^{131}$ I with those treated by ${ }^{131} \mathrm{I}$ alone showed that combined treatment might induce a faster resolution of systemic and local symptoms than ${ }^{131}$ I alone. In addition, for three patients, no ${ }^{131} \mid$ treatment was needed after LA [27].

\section{Malignant Thyroid Tumours}

Even though surgical excision remains the first therapeutic option in patients with thyroid cancer, both for primary disease and for recurrence, in recent years LA has been successfully applied to treat patients unsuitable for surgery with promising results $[17,24,28]$. 
The incidence of thyroid cancer has increased in the last decades, but without a concomitant increase in mortality. This fact might well reflect an increase in the early diagnosis of indolent tumours, which might have never affected the patient's life. Thus, these tumours, which once detected generally require surgical treatment, can be regarded as overdiagnosed and overtreated [16,59-62]. In order to reduce the adverse events associated with overtreatment, some authors have suggested applying an active surveillance strategy to small micropapillary thyroid carcinomas [63-65]. In between these two strategies, percutaneous thermal ablation has been proposed as a possible strategy of care, minimising the invasiveness of the treatment, in order to compensate for overdiagnosis and to reduce

Table 1. Characteristics and results of studies on laser ablation of recurrent thyroid cancers

\begin{tabular}{|c|c|c|c|c|c|}
\hline Study & Year & $\begin{array}{l}\text { No. of } \\
\text { patients }\end{array}$ & $\begin{array}{l}\text { No. of treated } \\
\text { tumours }\end{array}$ & Tumour dimensions & Result \\
\hline \multirow[t]{5}{*}{ Papini et al. [15] } & 2013 & 5 & 8 & Mean: $0.64 \pm 0.58 \mathrm{~mL}$ & Technical success: 100\%; no major complications \\
\hline & & & & & 12-Month follow-up \\
\hline & & & & & Mean volume reduction $87.72 \% \pm 0.11 \%$ \\
\hline & & & & & Mean serum Tg on LT4 decreased from $8.0 \pm 3.2$ to $2.0 \pm 2.5 \mathrm{ng} / \mathrm{mL}$ \\
\hline & & & & & Undetectable serum levels of Tg: $3 / 5$ patients (60\%) \\
\hline \multirow[t]{9}{*}{ Mauri et al. $[14]^{2)}$} & 2013 & 15 & 24 & $\begin{array}{l}\text { Mean: } 1.1 \pm 0.4 \mathrm{~cm} \\
\text { (range, } 0.6-1.6 \mathrm{~cm} \text { ) }\end{array}$ & Technical success: 100\%; no major complications \\
\hline & & & & & 6-Month follow-up \\
\hline & & & & & Local control: $11 / 15$ patients (73\%) \\
\hline & & & & & Negative on ${ }^{18}$ FDG-PET/CT and CEUS: 20/24 nodes (83\%) \\
\hline & & & & & Normalized serum Tg/TgAb: 6/15 patients (40\%) \\
\hline & & & & & 12-Month follow-up \\
\hline & & & & & Local control: 10/14 patients (71.4\%) \\
\hline & & & & & Negative on ${ }^{18}$ FDG-PET/CT and CEUS: $16 / 20$ nodes (80\%) \\
\hline & & & & & Normalized serum $\mathrm{Tg} / \mathrm{TgAb}$ : 4/10 patients (40\%) \\
\hline \multirow[t]{6}{*}{ Mauri et al. [24] } & 2016 & 24 & 46 & $\begin{array}{l}\text { Mean: } 1.0 \pm 0.5 \mathrm{~cm} \\
\text { (range, } 0.6-1.6 \mathrm{~cm} \text { ) }\end{array}$ & Technical success: 100\%; no major complications \\
\hline & & & & & Mean follow-up of $30 \pm 11$ months \\
\hline & & & & & $\operatorname{Tg}$ decreased from $8.40 \pm 9.25$ to $2.73 \pm 4.00 \mathrm{ng} / \mathrm{mL}$ \\
\hline & & & & & $\mathrm{Tg} / \mathrm{TgAb}$ normalized: $11 / 24$ patients (45.8\%) \\
\hline & & & & & $\begin{array}{l}\text { Local control: } 40 / 46 \text { lymph nodes (86.9\%), no residual disease at } \\
\text { imaging: 19/24 patients (79.1\%) }\end{array}$ \\
\hline & & & & & Estimated mean time to progression: $38.6 \pm 2.7$ months \\
\hline \multirow[t]{4}{*}{ Zhou et al. [70] } & 2016 & 21 & 27 & $\begin{array}{l}\text { Mean volume: } \\
105.42 \pm 114 \mathrm{~mm}^{3}\end{array}$ & Technical success: 100\%; no major complications \\
\hline & & & & & $\begin{array}{l}\text { Completely treated with } 1 \text { ablation: } 24 / 27 \text { lymph nodes (88.8\%), } \\
\text { completely treated with } 2 \text { ablations: } 3 / 27 \text { (12.2\%) }\end{array}$ \\
\hline & & & & & Significant volumetric reduction to $0.8-2.4 \mathrm{~mm}^{3}$ at the final follow-up \\
\hline & & & & & No regrowth or new lesions at US during follow-up \\
\hline Zhang et al. [69] & 2018 & 17 & 21 & $\begin{array}{l}\text { Mean volume: } \\
0.110 \pm 0.125 \mathrm{~mL} \\
\text { (interquartile range, } \\
0.01-0.536 \mathrm{~mL} \text { ) }\end{array}$ & Technical success: 100\%; no major complications \\
\hline
\end{tabular}

Completely ablated in 1 ablation: 18/21 cases (85.7\%), completely ablated with 2 ablations: $3 / 21$ (14.3\%)

Mean follow-up of $17.86 \pm 4.704$ months (interquartile range, $12-27$ months): no evident recurrence on US

Tg, thyroglobulin; LT4, levothyroxine; ${ }^{18}$ FDG-PET/CT, ${ }^{18}$-Fludeoxyglucose positron emission tomography computed tomography; CEUS, contrast-enhanced ultrasonography; TgAb, anti-thryoglobulin antibody; US, ultrasonography.

a) Preliminary results. 
the negative effects of overtreatment $[66,67]$.

Lee et al. [68], in an ex vivo study, performed LA immediately after thyroidectomy in three patients with papillary thyroid cancer. Histological analysis of the specimens demonstrated no viable tumour cells, and tumour safety margins comparable to those obtained through surgery. In 2011, Papini et al. [16] treated an incidental papillary thyroid microcarcinoma (PTMC) with LA in a patient at high surgical risk. The procedure was well tolerated, without complications. Ultrasound-guided fine-needle aspiration biopsy and core-needle biopsy performed 12 months after LA demonstrated necrotic material and inflammatory cells with no viable neoplastic cells [58]. Valcavi et al. [17] treated 3 patients with a single PTMC in the operating room under general anaesthesia immediately before surgical removal of the thyroid gland. In all cases, pathology demonstrated irreversible damage of the ablated neoplastic tissue. However, in two cases, papillary microfoci were identified in the removed thyroid gland, and in one case a lymph node micrometastasis was observed. This highlights one of the main issues of IGTA in thyroid malignant tumours, which is related to the inability of ultrasonography to detect very small tumour foci within the thyroid or in locoregional lymph nodes. Subsequently, Zhang et al. [45] published a larger series of 64 cases of PTMC treated with LA. Two incomplete ablations were detected by CEUS performed immediately after the procedure and a complementary ablation was successfully performed. Ultrasound-guided fine-needle aspiration at 1,6 , and 12 months after treatment did not show any residual tumour. No regrowth of treated lesions could be detected during a mean follow-up of $25.7 \pm 8.2$ months (range, 12 to 42 months). A cervical metastatic lymph node was detected on ultrasound and cytologically confirmed at 30 months after treatment [45]. Thus, even if the present evidence is limited, LA seems to represent a feasible and valuable therapeutic option for the treatment of small PTMC.

LA has also been demonstrated to be safe and effective for treating recurrent papillary thyroid carcinomas (PTCs) [69] (see Table 1). Zhou et al. [70] published a retrospective study, conducted in 21 patients with 27 recurrent PTC lesions treated with LA. Recurrent PTCs were identified during routine ultrasound follow-up after surgery. Twenty-four lesions received one ablation each and were completely ablated. Three incompletely ablated lesions detected on CEUS received a subsequent successful ablation. The mean follow-up was $14.9 \pm 5.9$ months (range, 6 to 24 months) [70]. In metachronous cervical nodal metastases from PTC, LA may reduce or delay highly invasive repeat neck dissections, especially in highrisk patients. In 2013, Papini et al. [15] reported on the treatment with $L A$ of five patients with previous total thyroidectomy and neck dissection, with eight new lymph node metastases with a volume less than $5 \mathrm{~mL}$ and no radioiodine uptake at a post-therapeutic
${ }^{131}$ I whole-body scan. A single LA was carried out without major complications. Treatment induced the progressive shrinkage of metastatic lymph nodes in all patients and no regrowth of the successfully treated lesions was detected. Colour Doppler and CEUS studies demonstrated an absence of vascularization. Mauri et al. [24] used LA to treat 24 patients with elevated serum levels of thyroglobulin or anti-thyroglobulin antibodies and a total of 46 metachronous nodal metastases. All patients had previously undergone surgery and radioiodine ablation, were at high surgical risk, and had a negative radioiodine scan. The authors obtained technical success in all 46 lymph nodes (100\%) with no major complications. Thyroglobulin levels decreased from $8.40 \pm 9.25 \mathrm{ng} / \mathrm{mL}$ before treatment to $2.73 \pm 4.0 \mathrm{ng} / \mathrm{mL}$ after treatment $(P=0.011)$, with serological conversion in 11 of 24 patients $(45.8 \%)$. Local control was obtained in 40 of the 46 lymph nodes (86.9\%) over a follow-up of $30 \pm 11$ months, and no residual disease was identified on imaging in 19 of 24 patients (79.1\%). Local control was achieved in 40 of the 46 lymph nodes (86.9\%) at 1 year and in all of the 25 nodes $(100 \%)$ that were followed for 3 years, with an estimated mean time to progression of $38.6 \pm 2.7$ months.

\section{Conclusion}

In conclusion, LA is a feasible, safe, and effective technique for the treatment of benign thyroid disease. LA may lead to resolution of clinical symptoms in the vast majority of cases, with reduced invasiveness, a low complication rate, and maintenance of gland function. Thus, this treatment can be considered as an effective alternative to surgery in patients with benign thyroid nodules. Additionally, it may be possible to use LA safely in the treatment of malignant thyroid cancer, both primary and metastatic. However, the evidence of efficacy of LA in malignant disease is still limited, and at present, this technique can only be considered after careful multidisciplinary evaluation in cases not suitable for standard therapies.

ORCID: Giovanni Mauri: https://orcid.org/0000-0003-4726-2692; Luca Nicosia: https://orcid.org/0000-0003-3979-8075; Gianluca Maria Varano: https://orcid. org/0000-0003-4505-5841; Daniele Maiettini: https://orcid.org/0000-0003-44217941; Franco Orsi: https://orcid.org/0000-0002-7330-0499; Luigi Solbiati: https:// orcid.org/0000-0002-3109-1449; Enrico Papini: https://orcid.org/0000-0003-47902733; Claudio Maurizio Pacella: https://orcid.org/0000-0002-7102-7839; Luca Maria Sconfienza: https://orcid.org/0000-0003-0759-8431

\section{Conflict of Interest}

C.M.P. and G.M. are consultants for Elesta s.r.l. All other authors have no conflict of interest. 


\section{References}

1. Kilfoy BA, Zheng T, Holford TR, Han X, Ward MH, Sjodin A, et al. International patterns and trends in thyroid cancer incidence, 19732002. Cancer Causes Control 2009;20:525-531.

2. Li MH, Liu JT. Screening of benign and malignant thyroid nodules in 5196 physical examination population. Zhonghua Zhong Liu Za Zhi 2018;40:151-154.

3. Papini E, Gugliemi R, Pacella CM. Laser, radiofrequency, and ethanol ablation for the management of thyroid nodules. Curr Opin Endocrinol Diabetes Obes 2016;23:400-406.

4. Gharib H, Papini E, Garber JR, Duick DS, Harrell RM, Hegedus L, et al. American Association of Clinical Endocrinologists, American College of Endocrinology, and Associazione Medici Endocrinologi medical guidelines for clinical practice for the diagnosis and management of thyroid nodules, 2016 Update. Endocr Pract 2016;22:622-639.

5. Papini E, Guglielmi R, Bizzarri G, Pacella CM. Ultrasound-guided laser thermal ablation for treatment of benign thyroid nodules. Endocr Pract 2004;10:276-283.

6. Tamhane S, Gharib H. Thyroid nodule update on diagnosis and management. Clin Diabetes Endocrinol 2016;2:17.

7. Durante C, Grani G, Lamartina L, Filetti S, Mandel SJ, Cooper DS. The diagnosis and management of thyroid nodules: a review. JAMA 2018;319:914-924.

8. Spiezia S, Garberoglio R, Milone F, Ramundo V, Caiazzo C, Assanti $A P$, et al. Thyroid nodules and related symptoms are stably controlled two years after radiofrequency thermal ablation. Thyroid 2009;19:219-225.

9. Che $Y$, Jin S, Shi C, Wang L, Zhang $X$, Li Y, et al. Treatment of benign thyroid nodules: comparison of surgery with radiofrequency ablation. AJNR Am J Neuroradiol 2015;36:1321-1325.

10. Jeong WK, Baek JH, Rhim H, Kim YS, Kwak MS, Jeong HJ, et al. Radiofrequency ablation of benign thyroid nodules: safety and imaging follow-up in 236 patients. Eur Radiol 2008;18:1244-1250.

11. Mainini AP, Monaco C, Pescatori LC, De Angelis C, Sardanelli F, Sconfienza LM, et al. Image-guided thermal ablation of benign thyroid nodules. J Ultrasound 2017;20:11-22.

12. Mauri G, Sconfienza LM. Percutaneous ablation holds the potential to substitute for surgery as first choice treatment for symptomatic benign thyroid nodules. Int J Hyperthermia 2017;33:301-302.

13. Jeong SY, Baek JH, Choi YJ, Lee JH. Ethanol and thermal ablation for malignant thyroid tumours. Int J Hyperthermia 2017;33:938945.

14. Mauri G, Cova L, Tondolo T, lerace T, Baroli A, Di Mauro E, et al. Percutaneous laser ablation of metastatic lymph nodes in the neck from papillary thyroid carcinoma: preliminary results. J Clin Endocrinol Metab 2013;98:E1203-E1207.

15. Papini E, Bizzarri G, Bianchini A, Valle D, Misischi I, Guglielmi R, et al. Percutaneous ultrasound-guided laser ablation is effective for treating selected nodal metastases in papillary thyroid cancer. J Clin Endocrinol Metab 2013;98:E92-E97.

16. Papini E, Guglielmi R, Gharib H, Misischi I, Graziano F, Chianelli $M$, et al. Ultrasound-guided laser ablation of incidental papillary thyroid microcarcinoma: a potential therapeutic approach in patients at surgical risk. Thyroid 2011;21:917-920.

17. Valcavi R, Piana S, Bortolan GS, Lai R, Barbieri V, Negro R. Ultrasound-guided percutaneous laser ablation of papillary thyroid microcarcinoma: a feasibility study on three cases with pathological and immunohistochemical evaluation. Thyroid 2013;23:1578-1582.

18. Baek JH, Kim YS, Sung JY, Choi H, Lee JH. Locoregional control of metastatic well-differentiated thyroid cancer by ultrasoundguided radiofrequency ablation. AJR Am J Roentgenol 2011;197:W331-W336.

19. Chung SR, Suh CH, Baek JH, Park HS, Choi YJ, Lee JH. Safety of radiofrequency ablation of benign thyroid nodules and recurrent thyroid cancers: a systematic review and meta-analysis. Int J Hyperthermia 2017;33:920-930.

20. Kim JH, Baek JH, Lim HK, Ahn HS, Baek SM, Choi YJ, et al. 2017 Thyroid radiofrequency ablation guideline: Korean Society of Thyroid Radiology. Korean J Radiol 2018;19:632-655.

21. Mauri G, Pisani Mainini A, Monaco C, Pescatori LC, De Angelis C, Sconfienza LM. Urgent need to apply a common language in image-guided thermal ablations. J Ultrasound 2018;21:77-78.

22. Pacella CM, Francica G, Di Lascio FM, Arienti V, Antico E, Caspani $B$, et al. Long-term outcome of cirrhotic patients with early hepatocellular carcinoma treated with ultrasound-guided percutaneous laser ablation: a retrospective analysis. I Clin Oncol 2009;27:2615-2621.

23. Tombesi P, Di Vece F, Sartori S. Laser ablation for hepatic metastases from neuroendocrine tumors. AJR Am J Roentgenol 2015;204:W732.

24. Mauri G, Cova L, lerace T, Baroli A, Di Mauro E, Pacella CM, et al. Treatment of metastatic lymph nodes in the neck from papillary thyroid carcinoma with percutaneous laser ablation. Cardiovasc Intervent Radiol 2016;39:1023-1030.

25. Sartori S, Mauri G, Tombesi P, Di Vece F, Bianchi L, Pacella CM. Ultrasound-guided percutaneous laser ablation is safe and effective in the treatment of small renal tumors in patients at increased bleeding risk. Int J Hyperthermia 2018;35:19-25.

26. Pacella CM, Bizzarri G, Guglielmi R, Anelli V, Bianchini A, Crescenzi $A$, et al. Thyroid tissue: US-guided percutaneous interstitial laser ablation: a feasibility study. Radiology 2000;217:673-677.

27. Chianelli M, Bizzarri G, Todino V, Misischi I, Bianchini A, Graziano $F$, et al. Laser ablation and 131-iodine: a 24-month pilot study of combined treatment for large toxic nodular goiter. J Clin Endocrinol Metab 2014;99:E1283-E1286.

28. Gambelunghe G, Stefanetti E, Colella R, Monacelli M, Avenia N, De 
Feo P. A single session of laser ablation for toxic thyroid nodules: three-year follow-up results. Int J Hyperthermia 2018;34:631-635.

29. Amabile G, Rotondi M, Pirali B, Dionisio R, Agozzino L, Lanza M, et al. Interstitial laser photocoagulation for benign thyroid nodules: time to treat large nodules. Lasers Surg Med 2011;43:797-803.

30. Papini E, Rago T, Gambelunghe G, Valcavi R, Bizzarri G, Vitti P, et al. Long-term efficacy of ultrasound-guided laser ablation for benign solid thyroid nodules: results of a three-year multicenter prospective randomized trial. J Clin Endocrinol Metab 2014;99:3653-3659.

31. Stafford RJ, Fuentes D, Elliott AA, Weinberg JS, Ahrar K. Laserinduced thermal therapy for tumor ablation. Crit Rev Biomed Eng 2010;38:79-100.

32. Schena E, Saccomandi P, Fong Y. Laser ablation for cancer: past, present and future. J Funct Biomater 2017;8:E19.

33. Saccomandi P, Schena E, Giurazza F, Del Vescovo R, Caponero $M A$, Mortato $L$, et al. Temperature monitoring and lesion volume estimation during double-applicator laser-induced thermotherapy in ex vivo swine pancreas: a preliminary study. Lasers Med Sci 2014:29:607-614.

34. Fuentes D, Feng Y, Elliott A, Shetty A, McNichols RJ, Oden JT, et al. Adaptive real-time bioheat transfer models for computer-driven MR-guided laser induced thermal therapy. IEEE Trans Biomed Eng 2010;57:1024-1030.

35. Jacques SL. Laser-tissue interactions. Photochemical, photothermal, and photomechanical. Surg Clin North Am 1992;72:531-558.

36. Goldberg SN, Gazelle GS, Halpern EF, Rittman WJ, Mueller PR, Rosenthal DI. Radiofrequency tissue ablation: importance of local temperature along the electrode tip exposure in determining lesion shape and size. Acad Radiol 1996;3:212-218.

37. Thomsen S. Pathologic analysis of photothermal and photomechanical effects of laser-tissue interactions. Photochem Photobiol 1991;53:825-835.

38. Larson TR, Bostwick DG, Corica A. Temperature-correlated histopathologic changes following microwave thermoablation of obstructive tissue in patients with benign prostatic hyperplasia. Urology 1996;47:463-469.

39. Nixon IJ, Angelos P, Shaha AR, Rinaldo A, Williams MD, Ferlito A. Image-guided chemical and thermal ablations for thyroid disease: review of efficacy and complications. Head Neck 2018;40:21032115.

40. Mauri G, Cova L, Monaco CG, Sconfienza LM, Corbetta S, Benedini $S$, et al. Benign thyroid nodules treatment using percutaneous laser ablation (PLA) and radiofrequency ablation (RFA). Int J Hyperthermia 2017;33:295-299.

41. Pacella CM, Bizzarri G, Spiezia S, Bianchini A, Guglielmi R, Crescenzi $A$, et al. Thyroid tissue: US-guided percutaneous laser thermal ablation. Radiology 2004;232:272-280.

42. Ma S, Zhou P, Wu X, Tian S, Zhao Y. Detection of the single-session complete ablation rate by contrast-enhanced ultrasound during ultrasound-guided laser ablation for benign thyroid nodules: a prospective study. Biomed Res Int 2016;2016:9565364.

43. Achille G, Zizzi S, Di Stasio E, Grammatica A, Grammatica L. Ultrasound-guided percutaneous laser ablation in treating symptomatic solid benign thyroid nodules: our experience in 45 patients. Head Neck 2016;38:677-682.

44. Prada F, Bene MD, Fornaro R, Vetrano IG, Martegani A, Aiani L, et al. Identification of residual tumor with intraoperative contrastenhanced ultrasound during glioblastoma resection. Neurosurg Focus 2016;40:E7.

45. Zhang L, Zhou W, Zhan W, Peng Y, Jiang S, Xu S. Percutaneous laser ablation of unifocal papillary thyroid microcarcinoma: utility of conventional ultrasound and contrast-enhanced ultrasound in assessing local therapeutic response. World J Surg 2018;42:24762484.

46. Mauri G, Porazzi E, Cova L, Restelli U, Tondolo T, Bonfanti M, et al. Intraprocedural contrast-enhanced ultrasound (CEUS) in liver percutaneous radiofrequency ablation: clinical impact and health technology assessment. Insights Imaging 2014;5:209-216.

47. Mauri G, Nicosia L, Varano GM, Bonomo G, Della Vigna P, Monfardini $L$, et al. Tips and tricks for a safe and effective imageguided percutaneous renal tumour ablation. Insights Imaging 2017;8:357-363.

48. Ginat DT, Saad WE. Bowel displacement and protection techniques during percutaneous renal tumor thermal ablation. Tech Vasc Interv Radiol 2010;13:66-74.

49. Orlandi D, Sconfienza LM, Lacelli F, Bertolotto M, Sola S, Mauri G, et al. Ultrasound-guided core-needle biopsy of extra-ocular orbital lesions. Eur Radiol 2013;23:1919-1924.

50. Mauri G, Solbiati L. Virtual navigation and fusion imaging in percutaneous ablations in the neck. Ultrasound Med Biol 2015;41:898.

51. Mauri G, De Beni S, Forzoni L, D'Onofrio S, Kolev V, Lagana MM, et al. Virtual navigator automatic registration technology in abdominal application. Conf Proc IEEE Eng Med Biol Soc 2014;2014:55705574.

52. Papini E, Guglielmi R, Bizzarri G, Graziano F, Bianchini A, Brufani $C$, et al. Treatment of benign cold thyroid nodules: a randomized clinical trial of percutaneous laser ablation versus levothyroxine therapy or follow-up. Thyroid 2007;17:229-235.

53. Dossing H, Bennedbaek FN, Hegedus L. Long-term outcome following interstitial laser photocoagulation of benign cold thyroid nodules. Eur J Endocrinol 2011;165:123-128.

54. Oddo S, Felix E, Mussap M, Giusti M. Quality of life in patients treated with percutaneous laser ablation for non-functioning benign thyroid nodules: a prospective single-center study. Korean J Radiol 2018;19:175-184.

55. Pacella CM, Mauri G, Achille G, Barbaro D, Bizzarri G, De Feo P, et al. Outcomes and risk factors for complications of laser ablation 
for thyroid nodules: a multicenter study on 1531 patients. J Clin Endocrinol Metab 2015;100:3903-3910.

56. Ha EJ, Baek JH, Kim KW, Pyo J, Lee JH, Baek SH, et al. Comparative efficacy of radiofrequency and laser ablation for the treatment of benign thyroid nodules: systematic review including traditional pooling and bayesian network meta-analysis. J Clin Endocrinol Metab 2015;100:1903-1911.

57. Pacella CM. Image-guided thermal ablation of benign thyroid nodules. J Ultrasound 2017;20:347-349.

58. Pacella CM, Mauri $\mathrm{G}$. Is there a role for minimally invasive thermal ablations in the treatment of autonomously functioning thyroid nodules? Int J Hyperthermia 2018;34:636-638.

59. Jegerlehner S, Bulliard JL, Aujesky D, Rodondi N, Germann S, Konzelmann I, et al. Overdiagnosis and overtreatment of thyroid cancer: A population-based temporal trend study. PLoS One 2017;12:e0179387.

60. O'Grady TJ, Gates MA, Boscoe FP. Thyroid cancer incidence attributable to overdiagnosis in the United States 1981-2011. Int J Cancer 2015;137:2664-2673.

61. Muntean V, Domsa I, Zolog A, Piciu D, Fabian O, Bosu R, et al. Incidental papillary thyroid microcarcinoma: is completion surgery required? Chirurgia (Bucur) 2013;108:490-497.

62. Burman KD. Treatment of recurrent or persistent cervical node metastases in differentiated thyroid cancer: deceptively simple options. J Clin Endocrinol Metab 2012;97:2623-2625.

63. Griffin A, Brito JP, Bahl M, Hoang JK. Applying criteria of active surveillance to low-risk papillary thyroid cancer over a decade: how many surgeries and complications can be avoided? Thyroid 2017;27:518-523.

64. Brito JP, Ito Y, Miyauchi A, Tuttle RM. A clinical framework to facilitate risk stratification when considering an active surveillance alternative to immediate biopsy and surgery in papillary microcarcinoma. Thyroid 2016;26:144-149.

65. Haser GC, Tuttle RM, Su HK, Alon EE, Bergman D, Bernet V, et al. Active surveillance for papillary thyroid microcarcinoma: new challenges and opportunities for the health care system. Endocr Pract 2016;22:602-611.

66. Kim JH, Baek JH, Sung JY, Min HS, Kim KW, Hah JH, et al. Radiofrequency ablation of low-risk small papillary thyroidcarcinoma: preliminary results for patients ineligible for surgery. Int J Hyperthermia 2017;33:212-219.

67. Mauri G, Sconfienza LM. Image-guided thermal ablation might be a way to compensate for image deriving cancer overdiagnosis. Int J Hyperthermia 2016;33:489-490.

68. Lee J, Jung JH, Kim WW, Hwang SO, Park JY, Jeong JY, et al. Ultrasound-guided laser ablation using multidirectional-firing fiber for papillary thyroid carcinoma: an ex vivo study with evaluation of tumor cell viability. Photomed Laser Surg 2016;34:300-304.

69. Zhang L, Zhou W, Zhan W. Role of ultrasound in the assessment of percutaneous laser ablation of cervical metastatic lymph nodes from thyroid carcinoma. Acta Radiol 2018;59:434-440.

70. Zhou W, Zhang L, Zhan W, Jiang S, Zhu Y, Xu S. Percutaneous laser ablation for treatment of locally recurrent papillary thyroid carcinoma <15 mm. Clin Radiol 2016;71:1233-1239. 